\title{
A CASE REPORT OF CORNEAL TUNNEL ABSCESS FOLLOWING ND-YAG LASER CAPSULOTOMY
}

\author{
Syed Heena Kubravi ${ }^{1}$, Syed Tariq Qureshi², Khalid Kawoosa ${ }^{3}$ \\ ${ }_{1}^{1}$ Postgraduate Student, Department of Ophthalmology, GMC, Srinagar. \\ 2 Professor and HOD, Department of Ophthalmology, GMC, Srinagar. \\ ${ }^{3}$ Senior Resident, Department of Paediatrics, GMC, Srinagar.
}

HOW TO CITE THIS ARTICLE: Kubravi SH, Qureshi ST, Kawoosa K. A case report of corneal tunnel abscess following Nd-YAG laser capsulotomy. J. Evolution Med. Dent. Sci. 2017;6(56):4217-4218, DOI: 10.14260/Jemds/2017/914.

\section{PRESENTATION OF THE CASE}

We describe the case report of a patient who developed a corneal abscess following Nd:YAG laser treatment.

\section{History}

A 55-year-old woman, nondiabetic, non-hypertensive presented to eye OPD with complaints of pain, redness, watering and diminution of vision in right eye since 5 days.

There was a history of cataract extraction (phacoemulsification with PCIOL implantation) in right eye 45 days back followed by Nd:YAG laser capsulotomy 5 days back in the same eye. Post laser, patient developed redness associated with watering, discharge and pain with decreased vision. Patient had been using topical antibiotic steroid drops for 2 weeks following cataract surgery.

\section{Ocular Examination}

The visual acuity in right eye was finger counting up to $2 \mathrm{mts}$. The extraocular movements were normal. Lids were oedematous while conjunctiva was congested. Corneal examination showed a tunnel abscess at 12 o'clock extending to 9 o'clock $4 \mathrm{~mm} \times 4 \mathrm{~mm}$ surrounded by dense infiltrate and corneal oedema.

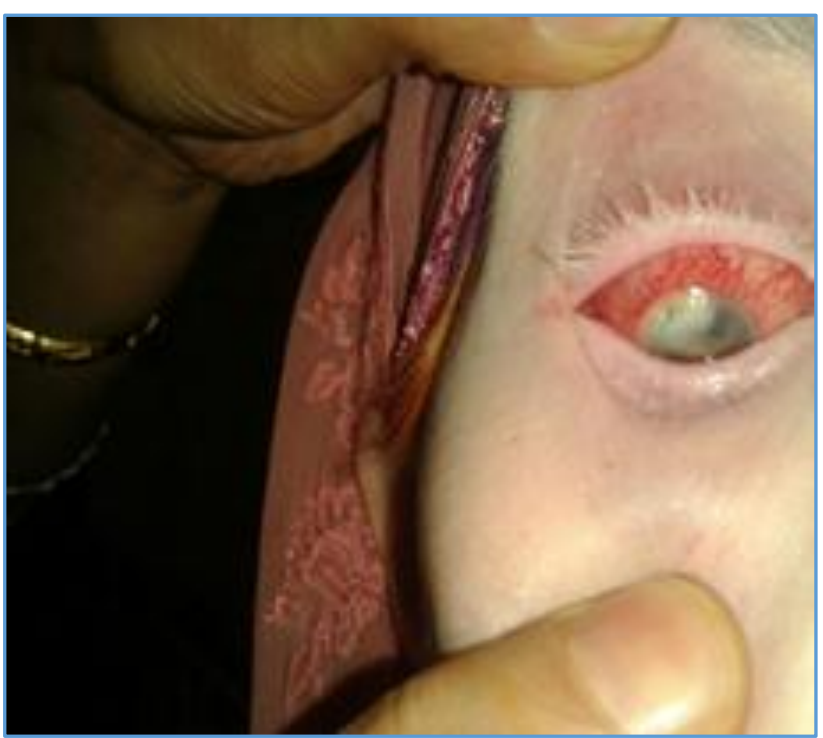

Figure 1

Financial or Other, Competing Interest: None. Submission 16-02-2017, Peer Review 01-07-2017,

Acceptance 07-07-2017, Published 13-07-2017.

Corresponding Author:

Dr. Syed Heena Kubravi,

Lane 7, H. No. 178, Badashah Colony,

Lal Bazar, Srinagar, Kashmir.

E-mail: syedheenak@gmail.com

DOI: $10.14260 /$ jemds $/ 2017 / 914$

\section{(c) $($ ) $\$$}

\section{DIFFERENTIAL DIAGNOSES}

1. Corneal ulcer.

2. Corneal abscess.

3. Endophthalmitis.

\section{CLINICAL DIAGNOSIS}

Corneal tunnel abscess.

\section{Management}

Topical medication was stopped for $24 \mathrm{hrs}$. and corneal scrapings were taken. Gram staining and $\mathrm{KOH}$ staining was done. $\mathrm{KOH}$ staining was negative while Gram stain revealed gram-positive cocci. Culture was done using blood agar, which revealed pneumococcus.

\section{Treatment}

Topical fortified cefazolin $5 \% \mathrm{e} / \mathrm{d}$ and topical fortified tobramycin $1.3 \%$ e/d were prescribed $1 \mathrm{hrly}$. for $48 \mathrm{hrs}$. f/b 2 hrly. during day and 4 hrly. at night for 7 days, then 6 hrly. for 2 weeks. Atropine 1\% e/d t.i.d. and lubricating eye drops 2 hrly. were added. Treatment was continued for 1 month following which patient improved symptomatically.

\section{DISCUSSION OF MANAGEMENT}

Photodisruption with neodymium-doped yttrium aluminium garnet (Nd:YAG) laser has been used to treat a number of complications arising after cataract surgery and IOL implantation. The optical breakdown of the laser pulse creates a pressure wave, which allows the surgeon to cut and manipulate various intraocular structures. It has been seen that Posterior Capsular Opacification (PCO) is one of the commonest complications of cataract surgery. Although, $\mathrm{Nd}$ :YAG laser is a safe and noninvasive technique for PCO, it is not without complications, some of which can be sight threatening. ${ }^{1}$ The technique of incision in cataract surgery has evolved from the conventional, large $12 \mathrm{~mm}$ wound closed with multiple sutures to small incision sclera tunnel and now to clear corneal tunnel incision. This incision used in phacoemulsification allows faster postoperative recovery and visual rehabilitation with minimum discomfort and less incidence of postoperative astigmatism. However, it has also been associated with an increased incidence of postoperative infections ranging from mild keratitis to endophthalmitis, which can result in severe loss of vision. ${ }^{2}$

$\mathrm{Nd}$ :YAG laser is now a standard procedure for treating secondary opacification of posterior capsule and contraction of anterior capsule following cataract surgery. This is a simple procedure in most cases, but is not without risks. Complications include IOL damage, IOL subluxation or dislocation, retinal detachment and secondary glaucoma. ${ }^{3}$ Corneal tunnel abscess, though rare, can occur as a complication following laser capsulotomy. Delayed postoperative endophthalmitis may also be rarely 
precipitated by Nd:YAG laser capsulotomy, which releases organisms into vitreous. ${ }^{4,5,6,7,8}$

The most common organisms isolated in corneal abscesses include Staphylococcus aureus, Staphylococcus epidermidis and Pneumococcus. The commonest sources of these organisms seem to be the normal flora of the eyelids or conjunctiva. Prolonged use of antibiotics and steroids following the surgery maybe an additional risk factor as it may result in selection of more virulent forms, which can invade the cornea. $9,10,11,12$

This case report illustrates the importance of extended followup following laser capsulotomy. Understanding the risk factors for development of postoperative infections is also crucial in prevention and management of such conditions. Proper preoperative preparation, use of sterile instruments, sterile operative technique and meticulous wound construction and closure during surgery can reduce the incidence of infections. In patients who develop infectious complications, urgent recognition and prompt referral is critical to optimal outcomes.

\section{FINAL DIAGNOSIS}

Corneal tunnel abscess following Nd:YAG laser capsulotomy.

\section{REFERENCES}

[1] Keates RH, Steinert RF, Puliafito CA, et al. Long-term follow-up of Nd: YAG laser posterior capsulotomy. J Am Intraocul Implant Soc 1984;10(2):164-8.

[2] Ammar MA, Samar A, Ashley B. Clear corneal incisions in cataract surgery. Middle East Afr J Ophthalmol 2014;21(1):25-31.

[3] Aron-Rosa D, Aron JJ, Griesemann M, et al. Use of the neodymium-YAG laser to open the posterior capsule after lens implant surgery: a preliminary report. J Am Intraocul Implant Soc 1980;6(4):352-4.
[4] Fankhauser F, Roussel P, Steffen J, et al. Clinical studies on the efficiency of high power laser radiation upon some structures of the anterior segment of the eye. First experiences of the treatment of some pathological conditions of the anterior segment of the human eye by means of a Q-switched laser system. Int Ophthalmol 1981;3(3):129-39.

[5] Charles S. Vitreoretinal complications of YAG laser capsulotomy. Ophthalmol Clin N Am 2001;14(4): 705-10.

[6] Carlson AN, Koch DD. Endophthalmitis following Nd: YAG laser posterior capsulotomy. Ophthalmic Surg 1988;19(3):168-70.

[7] Carlson AN, Stewart WC, King LP, et al. Staphylococcus aureus endophthalmitis following Nd: YAG laser capsulotomy. OMIG Publication of Abstracts 1993.

[8] Neuteboom GH, de Vries-Knoppert WA Endophthalmitis after Nd: YAG laser capsulotomy. Doc Ophthalmol 1988;70(2-3):175-8.

[9] Siganos CS, Solomon A, Frucht-Percy J. Microbiol findings in suture erosion after penetrating keratoplasty. Ophthalmology 1997;104(3):513-6.

[10] Ahmad BT, Steinemann TL. Suture related keratitis following cataract surgery caused by methicillin resistant staphylococcus aureus. Clin Ophthalmol 2010;4:179-82.

[11] Charteris DG, Batterbury M, Armstrong M, et al. Suppurative keratitis caused by streptococcus pneumoniae after cataract surgery. Br J Ophthalmol 1994;78(11):847-9.

[12] Cameron JA, Huaman A. Corneoscleral abscess resulting from a broken suture after cataract surgery. J Cataract Refract Surg 1994;20(1):82-3. 